\title{
Fast Dynamic Control of Damaged Historical Buildings: A New Useful Approach for Structural Health Monitoring after an Earthquake
}

\author{
Sergio Vincenzo Calcina, Luca Piroddi, and Gaetano Ranieri \\ Department of Civil Engineering, University of Cagliari, Environmental Engineering and Architecture (DICAAR), \\ Via Marengo 2, 09123 Cagliari, Italy \\ Correspondence should be addressed to Luca Piroddi; lucapiroddi@yahoo.it
}

Received 27 September 2013; Accepted 29 October 2013

Academic Editors: F. Hernández-Olivares and C. J. Leo

Copyright (C) 2013 Sergio Vincenzo Calcina et al. This is an open access article distributed under the Creative Commons Attribution License, which permits unrestricted use, distribution, and reproduction in any medium, provided the original work is properly cited.

\begin{abstract}
The structures damage conditions assessment requires numerous precautions to ensure the safety of people during site visits and inspections. Among several methods providing useful information about the conservation status of the structures, dynamic monitoring techniques are suitable to retrieve the global behavior of the buildings. The anomalous features diagnosis of the structural dynamic response is an index of alterations of the material state and, in the worst cases, is related to the presence of damaged structural elements. This paper proposes the use of remote control systems for the structural evaluation of the damage state of buildings and describes the results achieved in an interesting application: the experimental dynamic analysis carried out on the inaccessible damaged bell tower of the Church of Santi Giacomo and Filippo in Mirandola (Italy). The study is based on observations performed using the IBIS-S ground-based radar interferometer to remotely measure the displacements of several elements of the building above $0.01 \mathrm{~mm}$ amplitude. This totally noninvasive and nondestructive approach has proved to be reliably implemented as a useful method to structural health monitoring procedures and especially for extensive and fast inspection analyses aiming at the first evaluation of the damage level and the soundness of slender buildings after earthquakes.
\end{abstract}

\section{Introduction}

Structural damage identification is a fundamental element following an earthquake. A correct definition of the damage state of buildings allows us to establish technical procedures and operational standards for safeguarding the structures, aimed at restoring their original conditions.

Structural Health Monitoring techniques (SHM) make it possible to deduce the presence of lesions and estimate the severity of the damage to the structures by measuring the mode of vibration of the buildings. This is possible because the dynamic response of structures is strongly influenced by the conservation state of materials and by structural lesions. The scientific literature includes many methods of structural dynamic response evaluation and algorithms for the extraction of main modal parameters $[1,2]$. Several experimental configurations are classified in function of the number of measured output signals (number of sensors) and of the type of sources used to energize the structures. In this context, there are several experimental layouts to modal parameters identification. Specifically, it is possible to differentiate between forced vibration tests (i.e., using mechanical shaker or vibrodines), free vibration tests (i.e., by means of falling objects inside or outside the buildingsimpulsive signals), and ambient vibration tests (i.e., using random sources as wind and artificial noise) [3]. The last methods are very useful for assessing dynamic behavior and for a rapid evaluation of the true conditions of existing damaged structures after an earthquake. However, the most common data acquisition techniques use in-contact sensors. Velocimeters or accelerometers arrays are placed inside the building and are used to record time series of ambient vibration. In the last decade, advances in the field of Ground Based Remote Sensing assure remote data acquisition and 


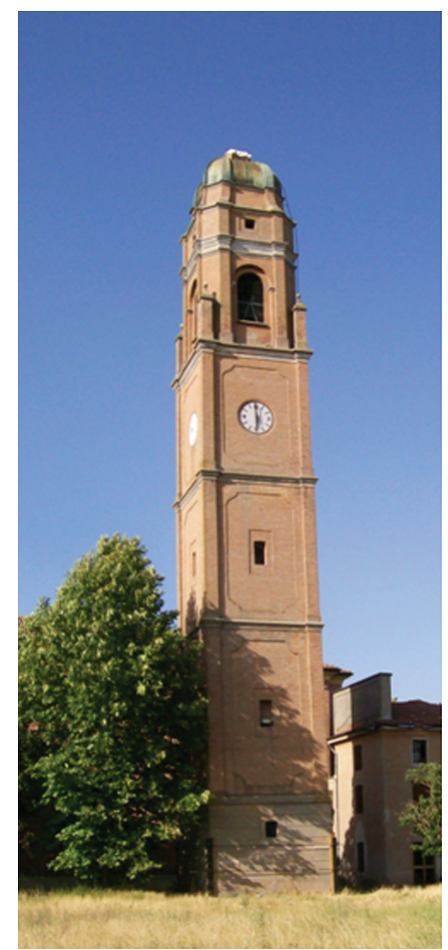

(a)

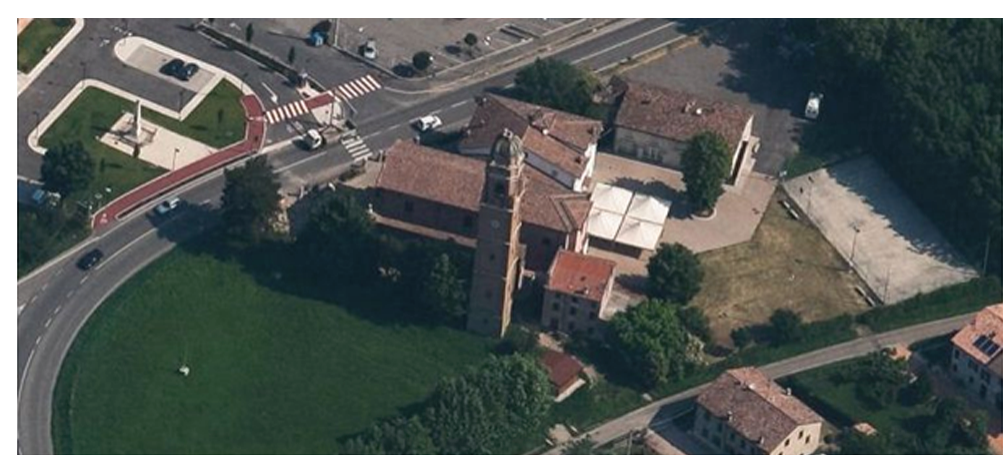

(b)

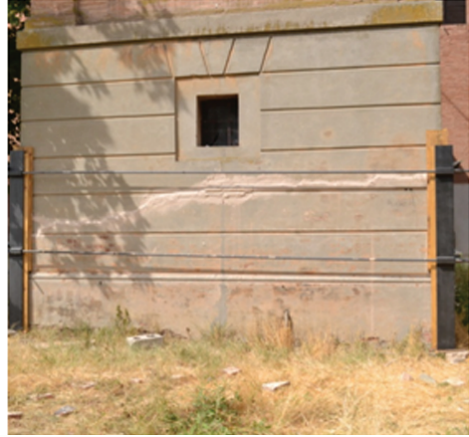

(c)

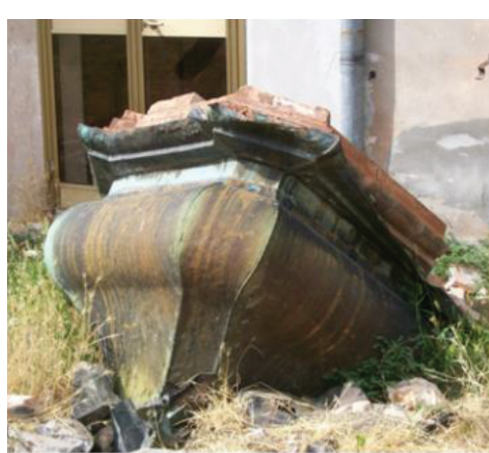

(d)

Figure 1: Some images of the damaged bell tower. (a) Southwest side of the building. (b) Panoramic view. (c) Cracks at the base of the tower. (d) Collapsed top.

real-time monitoring of vibrations in critical conditions, as well as dynamic control of severely damaged structures after earthquakes. In this paper, the authors propose a procedure for assessing the state of damage to structures in areas affected by earthquakes. This approach is founded on remote monitoring techniques of mechanical vibrations by means of interferometric surveys. This method allows us to ensure maximum safety conditions during the monitoring of potentially damaged structures. In fact, the assessment of the structural damages during the next phase is extremely delicate due to precarious stability conditions of structures and due to possible further aftershocks during technical inspections by specialists. For this reason, a new application of this proposed operational approach will be discussed in the case of the Emilia earthquake (Italy) for the stability control of the bell tower of San Giacomo Roncole using IBIS-S groundbased microwave interferometer.

1.1. Instrumental Features of the IBIS-S Technology. Microwave interferometry has recently emerged as a new technology, specifically suitable to remotely measure the vibration response of structures. Several authors observe that the interferometric technique has proven to be a useful remote sensing tool for vibration measurements of structures, such as architectural heritage structures [4-6], engineering infrastructures $[7,8]$, and vibrating stay cables $[9,10]$. This radar technology is founded on the combined use of highresolution waveforms [11] and interferometric technique [12]. This technique is implemented to compute the displacement of each target through the phase shift $\Delta \theta$ of the back-scattered microwave signals collected at different time intervals. The displacement along the radar line of sight $d_{r}$ is computed from the phase-shift with the following simple equation (1):

$$
d_{r}=-\frac{\lambda}{4 \pi} \Delta \theta
$$

where $\lambda$ is the wavelength of the signal [13]. The main advantages of the interferometric radar for structural health monitoring of civil infrastructures are high accuracy of measurements (sensitivity of $0.01-0.02 \mathrm{~mm}$ ) and high spatial resolution, simultaneous monitoring of several targets within the sensor applicable distance, independence from daylight and weather conditions for short recordings, portability, and quick set-up time. The sensor module is provided with two-horn antennas $\left(-3 \mathrm{~dB}\right.$ beamwidth of $17^{\circ}$ and $15^{\circ}$ in the horizontal and vertical plane) and transmits the electromagnetic signals in $\mathrm{Ku}$ frequency band from 17.1 to $17.3 \mathrm{GHz}$, receiving the echoes from several targets placed inside the radar scenario.

The acquired time history $s(t)$ is the displacement of the target projected along the sensor-target line of sight (LOS). The LOS displacement $s(t)$ is linked to the displacements components $V(t)$ and $H(t)$, in vertical and in horizontal plane respectively, through the following equation (2):

$$
s(t)=V(t) \sin (\beta)+H(t) \cos (\beta),
$$

with $\beta$ being the LOS angle computed from the horizontal axis. The interferometric survey may thus be considered a 


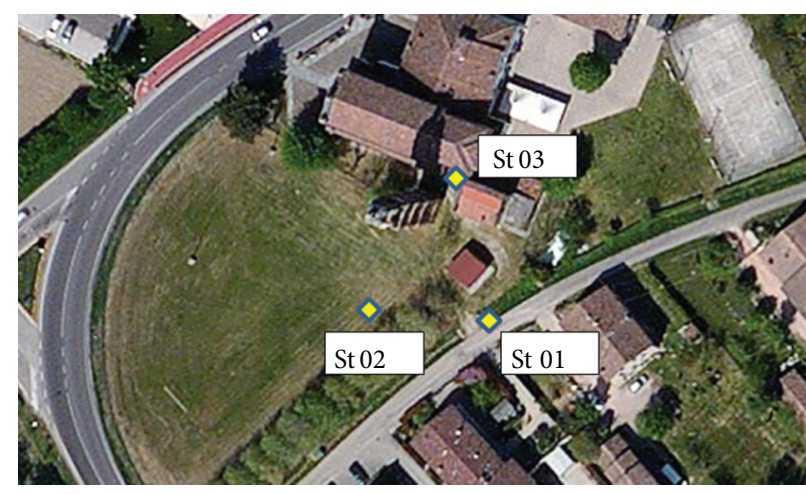

(a)

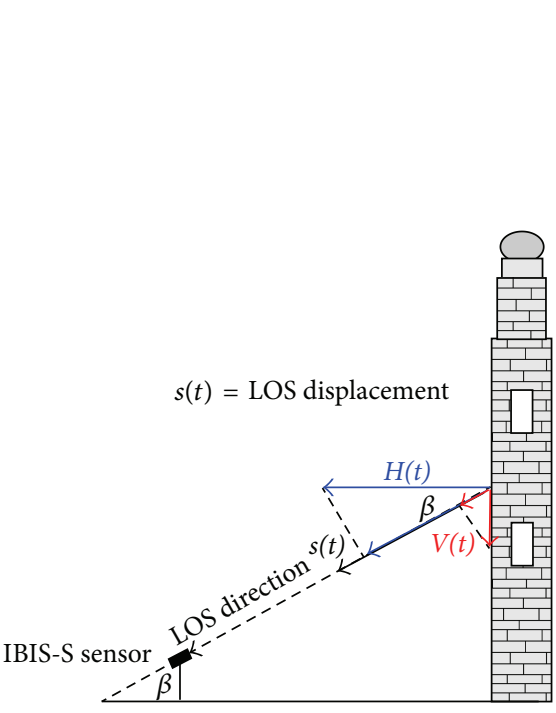

(b)

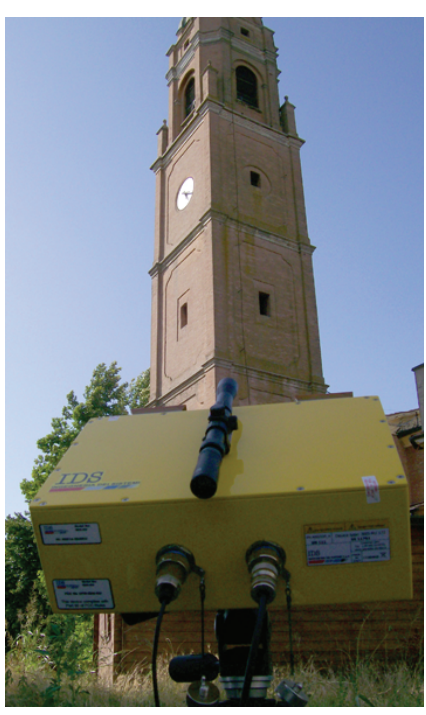

(c)

FIgURE 2: (a) Installation of the IBIS-S system in several acquisition stations placed at $25 \mathrm{~m}$ (St 01 ) and $23 \mathrm{~m}$ (St 02 ) from the base of the tower with LOS angle of $30^{\circ}$ (central beam) and at $8 \mathrm{~m}$ (St 03) with LOS angle of $70^{\circ}$ (central beam). (b) Radar line of sight displacement and true displacement vector. (c) Image of the IBIS-S system used during the experiments.

powerful tool to evaluate the deformation related to dynamic applied loads and to evaluate the stiffness of structures.

\section{Description and Method}

The test site was chosen in order to analyze a strongly damaged but not totally crushed bell tower, for which remote sensing approach was the only compatible one with safety conditions. The experimental settings were designed with the task to have comparable results from two main acquisition distances from the target and two different direction projections of measured displacement.

\subsection{The Tower: A Brief Historical Overview and Description} of the Damage. The Emilia earthquake has caused numerous damages to the structures. The buildings most affected by the earthquake are industrial structures (factories and storage magazines) and cultural heritage buildings (churches, bell towers, civic towers, etc.), whose geometric and constructive features have contributed to increasing their vulnerability in case of earthquakes. In this work, we present the study performed for the bell tower of San Giacomo Roncole. The actual structure was built from 1771 to 1774 with the same materials of the previous Carmelite Convent of Santa Maria delle Grazie della Galeazza [14]. The building is located few metres away from the singular nave of the church. The structure replaced an earlier tower, adjacent to the body of the church, and demolished by the damage caused by the vibrations of the bells. The new tower is a masonry structure located at southwest of the church. The tower reaches a height of about 36 metres with a square base ( 5 metres per side). After the earthquakes of the 20th and 29th May, 2012, (magnitude $M_{l}=5.9$ and $M_{l}=5.8$, resp.) the building sustained serious damage to the base, highlighted by displacements of about $2 \mathrm{~cm}$ toward the southwest side and of $1 \mathrm{~cm}$ on the southeast side. In other words, after the earthquake, the structure was shifted at the base, assuming an eccentric position. Also there are various fractures on the first section of the tower horizontally and diagonally crossing its perimeter walls, where a rigid motion on the order of 


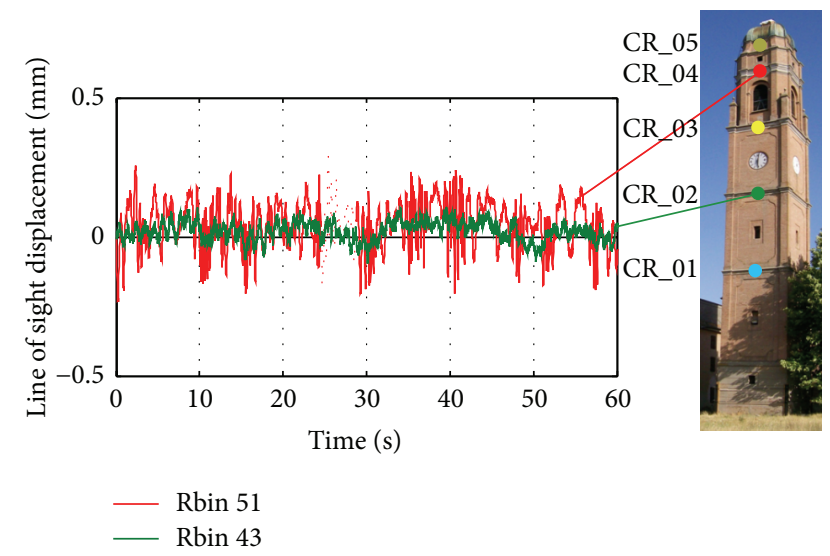

FIGURE 3: One-minute record acquired with the second configuration: LOS displacement retrieved from radar data as a function of the time. The time histories refer to two range bins selected from the radar power profile and correspond to different heights of the tower.

centimetres was measured. The top of the structure collapsed at about 9 metres from the base toward the southwest side (see Figure 1).

2.2. Sensor Installation and Processing of Data. The tower of San Giacomo Roncole is a slim structure with a shape characterized by several natural corners (see Figure 2). Consequently, the measurements are performed without artificial corner reflectors installed on the body surface of the structure. This is an essential condition because the structure is seriously damaged. Dynamic surveys are carried out using three different configurations. In the first one, the IBIS-S system was placed in front of the tower in the southeast direction in order to monitor the dynamic behavior of the full body of the structure with $30^{\circ}$ LOS angle, computed for the emitting cone axis of the radar sensor. The second radar station was placed in the southwest direction $\left(30^{\circ}\right.$ LOS angle). The last acquisition was performed with the IBIS-S system located under the tower ( $70^{\circ}$ LOS angle). The acquisition geometry was selected in order to reduce the effects of all possible noise sources, such as suspended cables and other metal structures or trees and vegetation inside the radar profile. Each acquisition had a duration of about $10 \mathrm{~min}$ with a sampling frequency of $200 \mathrm{~Hz}$. The vibrations of the building were monitored in real time during field operations. The Fourier spectra of signals were provided by processing the acquired data with IBIS Dataviewer and Matlab software in order to assess the main frequencies of the structure. Before of the spectral analysis, the displacement data were detrended and tapered with Hamming function to reduce leakage effects. We have applied the Frequency Domain Decomposition technique [15] based on singular values decomposition of the power spectral density matrix to identify the structural dynamic response of the tower. By using this decomposition method, main modal parameters can be identified with high accuracy even in the case of strong noise contamination of the signals.

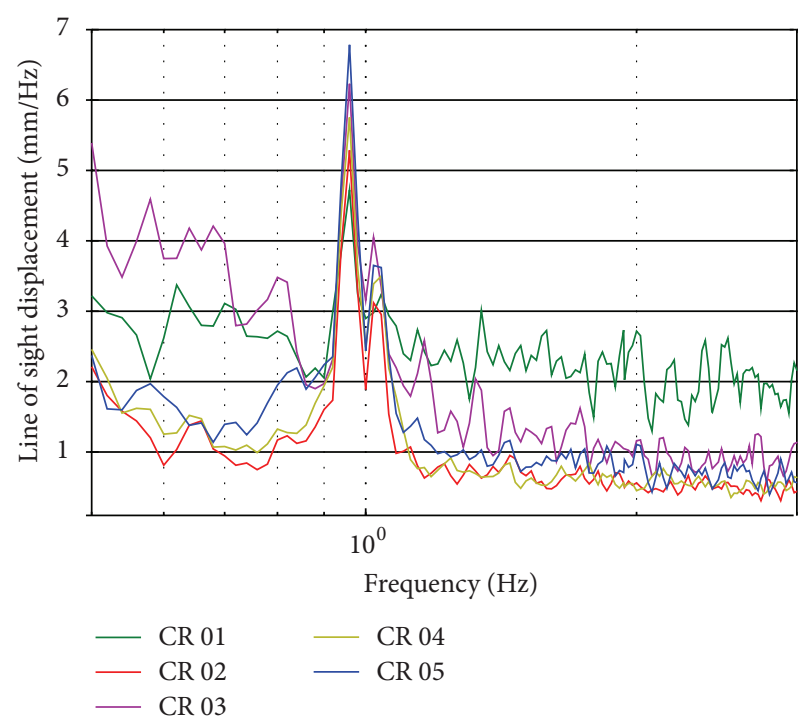

Figure 4: Displacement spectra calculated by using the entire 10 -minute record, for five different radar-bins with variable SNR achieved from data acquisition with configuration 1 .

\section{Results and Discussion}

The range bins with high signal-to-noise ratio (SNR) along the radar power profile are associated with different natural back-scatterers located inside the radar scenario. However, the signal-to-noise ratio of the radar response from this structure is high and the structure is isolated inside the radar scenario. Thus several range bins may be selected to be analyzed. Five range bins of the radar power profile are selected to estimate fundamental vibration properties of the structure by means of the FDD decomposition technique. The radar bins are selected in function of the distance along the radar line of sight between each radar-bin and the IBIS-S sensor. These range bins correspond to five reflective points placed on the bell tower facade. This operation is easily performed knowing the geometric characteristics of the tower (the height of several architectonic elements such as windows and other ledges), the horizontal distance of the radar station, and the inclination of the IBIS-S head. The displacements retrieved from radar data are shown in Figure 3 . These time series have been obtained observing the tower from a position to the base of the tower, at a distance of 23 metres (configuration 2). During all measurements, a regular wind with moderate speed of $5.5 \mathrm{~m} / \mathrm{s}$ blew.

The calculated displacement spectra, obtained over the whole recorded ten minutes signal, are shown in Figure 4. A band-pass filter $(0.3 \mathrm{~Hz}-10 \mathrm{~Hz})$ was applied to reduce the presence of disturbances linked to atmospheric effects and to vibration of the sensor itself. The influence of the first effect is prevalent on the measured phases and, as a consequence, on the estimated displacements with long period $(0.1-0.2 \mathrm{~Hz})$. Another effect is caused by the vibration of the measurement tool. Luzi et al. [16] observe that the measured resonant frequency of the system ranges within $10 \mathrm{~Hz} \pm 2 \mathrm{~Hz}$ for typical working conditions. Then a low-pass filtering may 


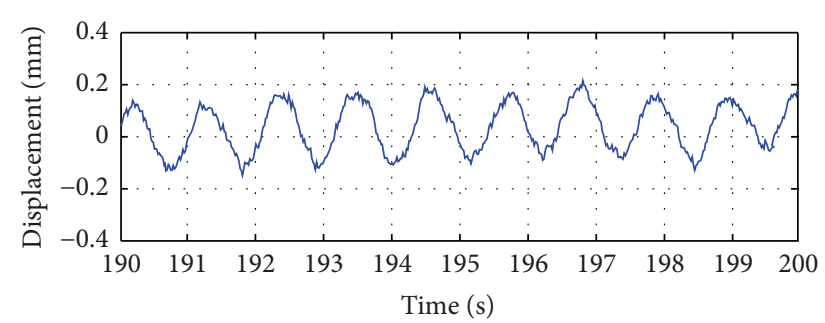

— Rbin 50

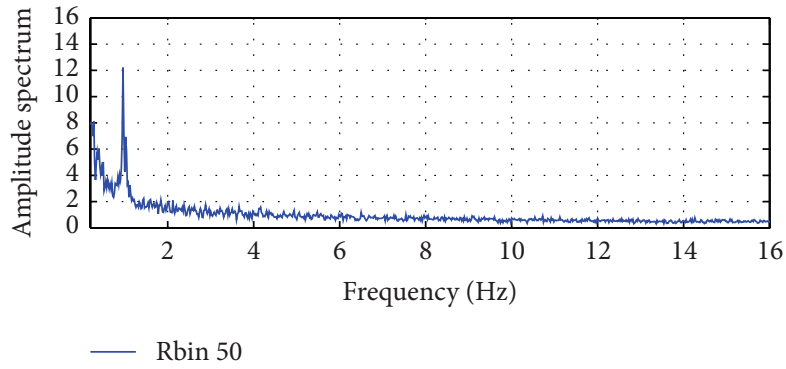

(b)

Figure 5: (a) Sinusoidal trend of the displacement record obtained for the 50th range bin (30 metres height). (b) Frequency analysis of the same time-history.

be applied in order to assure that the measured vibrations are not imputable to the natural response of the tripodhead sensor system. All amplitude spectra are characterized by a clear harmonic component at $0.96 \mathrm{~Hz}$ (corresponding period of $1.04 \mathrm{~s}$ ) whose amplitude increases with the height of the analysed range bin. This behavior agrees with the expected amplitude variation associated at the first natural mode (simple bending). This periodicity cannot be directly retrieved from all displacement time series but only for the 50th range bin corresponding to the reflection from the height of 30 metres on the tower (see Figure 5).

The obtained value of $0.96 \mathrm{~Hz}$ could be influenced by the presence of structural damage caused by the earthquake. This value could be compared with the theoretical one achieved through numerical modeling of the building before the damage. However, even without a direct model, several empirical relationships available for masonry structures, like those proposed by the Italian Building Code NTC-2008, the Spanish National Code NSCE-02, and by literature studies [17], are used to assess the fundamental frequency of vibration. The obtained results range between 1.4 and $1.5 \mathrm{~Hz}$. The significant difference $(31 \%-36 \%)$ between the experimental value and the estimated values could be imputed to the damage caused by the earthquake. It is generally recognised that the period of vibration grows while increasing the mass of the vibrating system and while reducing the stiffness.

The radar measurements allow the evaluation of the dynamic behavior (amplitude of vibration) of several parts of the building located at different heights. In this case we have monitored the structure from different perspectives and we have compared the experimental mode shapes obtained for the IBIS-S configurations 1 and 2. The mode shape retrieved by the configuration 3 was not used for this analysis because the displacements measured in LOS direction are not comparable with the others. In fact, in this configuration, the microwave sensor is more inclined $\left(70^{\circ}\right)$ and is placed at short distance from the tower (8 metres). Measured displacements along two directions are projected along the horizontal plane. The experimental mode shapes show a similar trend, as we can see in Figure 6. We observe that maximum values are measured from St 02 IBIS-S station and are characterized by amplitude ranges from 0.05 to $0.2 \mathrm{~mm}$. The fundamental mode of vibration is a bending mode with the same frequency of $0.96 \mathrm{~Hz}$ in both directions of measurement. Anomalous behavior is detected at the point placed at about 17 metres height with experimental measured displacements greater than those expected. At this level of the structure, we observe a significant increasing in the amplitude of the measured displacements with respect to the lower level (located at 11 metres height above the ground surface). There is an increase of $100 \%$ (acquisition station 1), moving from $0.04 \mathrm{~mm}$ to $0.08 \mathrm{~mm}$ of maximum amplitude at the first structural vibration frequency and an increase of $80 \%$ (acquisition station 2), from $0.05 \mathrm{~mm}$ to $0.09 \mathrm{~mm}$, which are not attributable to geometric differences in the two building levels or to largely variable construction features of the elevating structure. Therefore, this trend could be reliably correlated with the high structural damages of the building at the middle level. Moreover, the larger displacements obtained in the second acquisition are justified by the major shift recorded in this direction (about $2 \mathrm{~cm}$ ) due to seismic action.

\section{Conclusions}

This paper proposes the use of the ground-based microwave interferometry for remote sensing of vibrations of structures aimed at providing useful information for specialists about the damage state of structures in areas affected by earthquakes. For this reason, this work is the first application of ground-based radar interferometry to the study of an inaccessible damaged building. The authors report the results of the experimental dynamic test aimed at estimating the vibrations of an historical bell tower in an urban environment, performed through ambient vibration testing. Also, the basic principle of the interferometric technique has been briefly resumed and the main experimental data obtained for the vibration features of the structure have been critically discussed to identify anomalous dynamic behaviors linked to structural damages. In general, the proposed method can estimate displacements ranging from a few microns up to several millimetres for large structures, ranging from thin and tall structures to other types of buildings (towers, skyscrapers, and bridges). The possibility of working remotely makes this approach suitable for the dynamic control of buildings that have reported structural damage after an earthquake, 


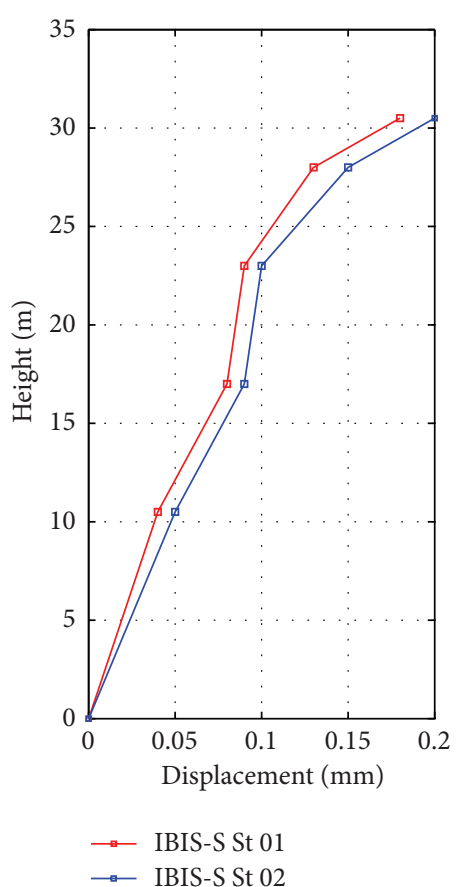

Figure 6: Comparison between the experimental mode shapes retrieved from two points of view of the IBIS-S system.

especially for civil structures of strategic interest during the emergency and for cultural heritage buildings which represent the history and the social identity of a community.

\section{Conflict of Interests}

The authors declare that there is no conflict of interests regarding the publication of this paper titled "Fast dynamic control of damaged historical buildings: a new useful approach for Structural Health Monitoring after an earthquake."

\section{Acknowledgments}

Sergio Vincenzo Calcina gratefully acknowledges Sardinia Regional Government for the financial support of her Ph.D. scholarship (P.O.R. Sardegna F.S.E. Operational Programme of the Autonomous Region of Sardinia, European Social Fund 2007-2013-Axis IV Human Resources, Objective 1.3, Line of Activity 1.3.1.). Luca Piroddi gratefully acknowledges Sardinia Regional Government for the financial support (P.O.R. Sardegna F.S.E. Operational Programme of the Autonomous Region of Sardinia, European Social Fund 2007-2013-Axis IV Human Resources, Objective 1.3, Line of Activity 1.3.1 "Avviso di chiamata per il finanziamento di Assegni di Ricerca").

\section{References}

[1] S. S. Ivanovic, M. D. Trifunac, and M. I. Todorovska, "Ambient vibration tests of structures: a review," Bulletin of Indian Society of Earthquake Technology, vol. 37, no. 4, article 407, pp. 165-197, 2000.

[2] H. Sohn, C. R. Farrar, F. M. Hemez et al., "A Review of structural health monitoring literature: 1996-2001,” Los Alamos National Laboratory Report LA-13976-MS, Los Alamos, NM, USA, 2004.

[3] N. M. M. Maia, J. M. M. Silva, J. He et al., Theoretical and Experimental Modal Analysis, Research Studies Press, New York, NY, USA, 1997.

[4] M. Pieraccini, M. Fratini, F. Parrini, G. Pinelli, and C. Atzeni, "Dynamic survey of architectural heritage by highspeed microwave interferometry," IEEE Geoscience and Remote Sensing Letters, vol. 2, no. 1, pp. 28-30, 2005.

[5] M. Pieraccini, M. Fratini, D. Dei, and C. Atzeni, "Structural testing of historical heritage site towers by microwave remote sensing," Journal of Cultural Heritage, vol. 10, no. 2, pp. 174-182, 2009.

[6] C. Atzeni, A. Bicci, D. Dei, M. Fratini, and M. Pieraccini, "Remote survey of the leaning tower of pisa by interferometric sensing," IEEE Geoscience and Remote Sensing Letters, vol. 7, no. 1, pp. 185-189, 2010.

[7] C. Gentile and G. Bernardini, "Output-only modal identification of a reinforced concrete bridge from radar-based measurements," NDT \& E International, vol. 41, no. 7, pp. 544-553, 2008.

[8] C. Gentile and G. Bernardini, "An interferometric radar for non-contact measurement of deflections on civil engineering structures: Laboratory and full-scale tests," Structure and Infrastructure Engineering, vol. 6, no. 5, pp. 521-534, 2010.

[9] C. Gentile, "Application of microwave remote sensing to dynamic testing of stay-cables," Remote Sensing, vol. 2, no. 1, pp. 36-51, 2010.

[10] C. Gentile, "Deflection measurement on vibrating stay cables by non-contact microwave interferometer," NDT \& E International, vol. 43, no. 3, pp. 231-240, 2010.

[11] D. R. Wehner, High-Resolution Radar, Artech House, London, UK, 2nd edition, 1995.

[12] F. M. Henderson and A. J. Lewis, Manual of Remote Sensing. Principles and Applications of Imaging Radar, Wiley, New York, NY, USA, 1998.

[13] J. D. Taylor, Ultra-Wideband Radar Technology, CRC Press, Boca Raton, Fla, USA, 2001.

[14] E. Andreoli, San Giacomo Roncole: Raccolta Di Notizie Storiografiche Popolari, Mirandola Edizioni, Mirandola, Italy, 1987.

[15] R. Brincker, L. Zhang, and P. Andersen, "Modal identification of output-only systems using frequency domain decomposition," Smart Materials and Structures, vol. 10, no. 3, pp. 441-445, 2001.

[16] G. Luzi, O. Monserrat, and M. Crosetto, "Real aperture radar interferometry as a tool for buildings vibration monitoring: limits and potentials from an experimental study," in Proceedings of the 10th International Conference on Vibration Measurements by Laser and Non-contact Techniques (AIVELA '12), pp. 309-317, Ancona, Italy, 2012.

[17] C. Rainieri and G. Fabbrocino, "Estimating the elastic period of Masonry towers," in Proceedings of the SEM IMAC 30th Conference, Society for Experimental Mechanics, Jacksonville, Fla, USA, 2012. 

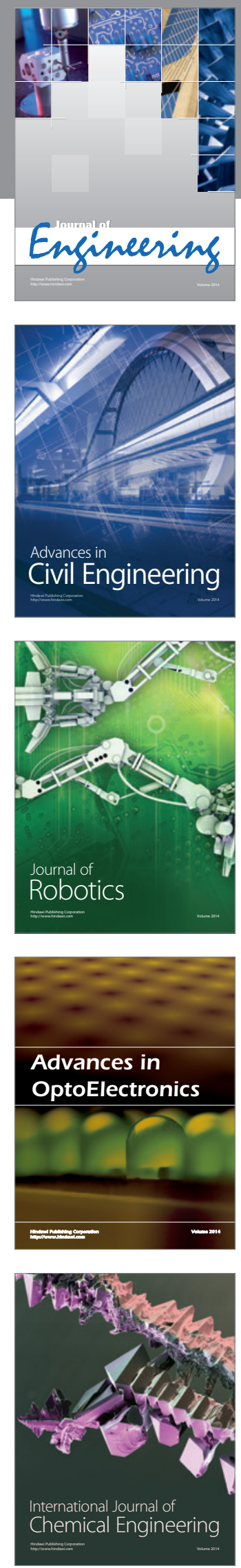

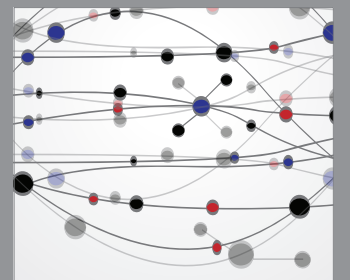

The Scientific World Journal
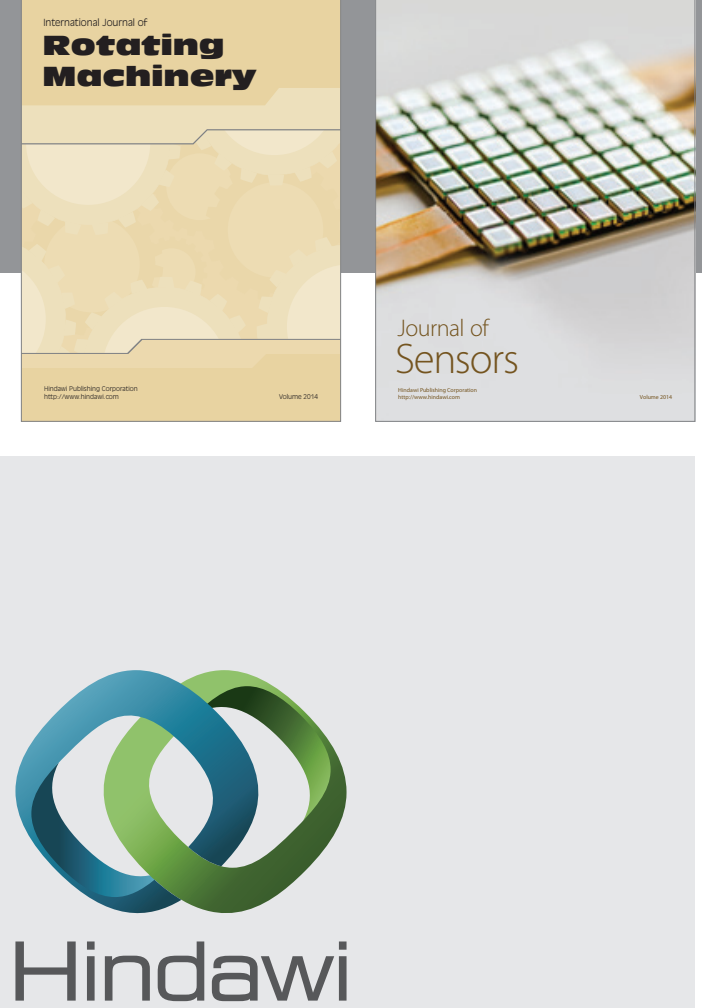

Submit your manuscripts at http://www.hindawi.com
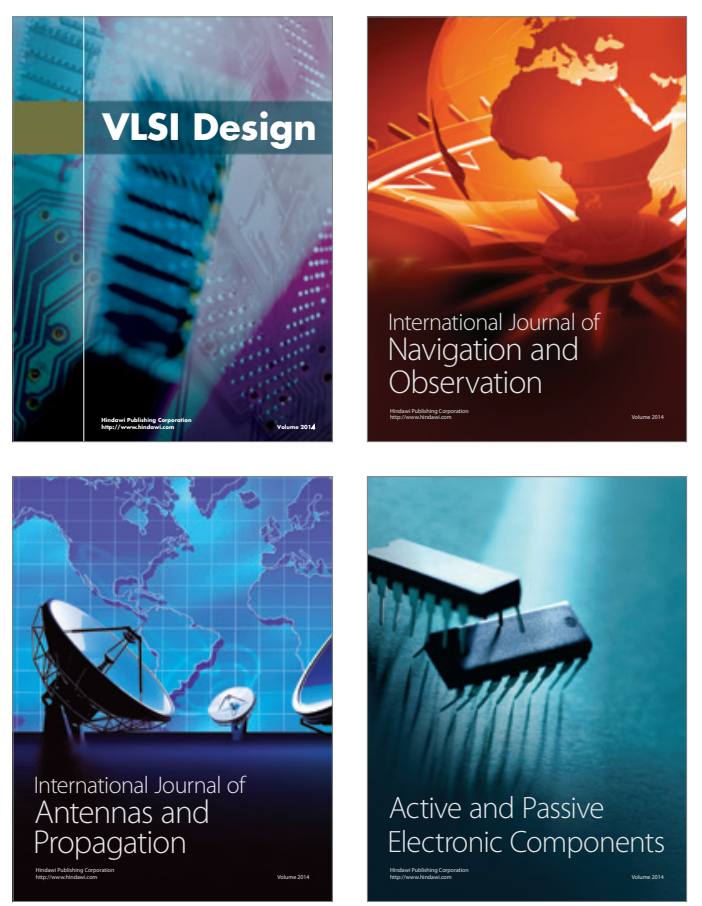
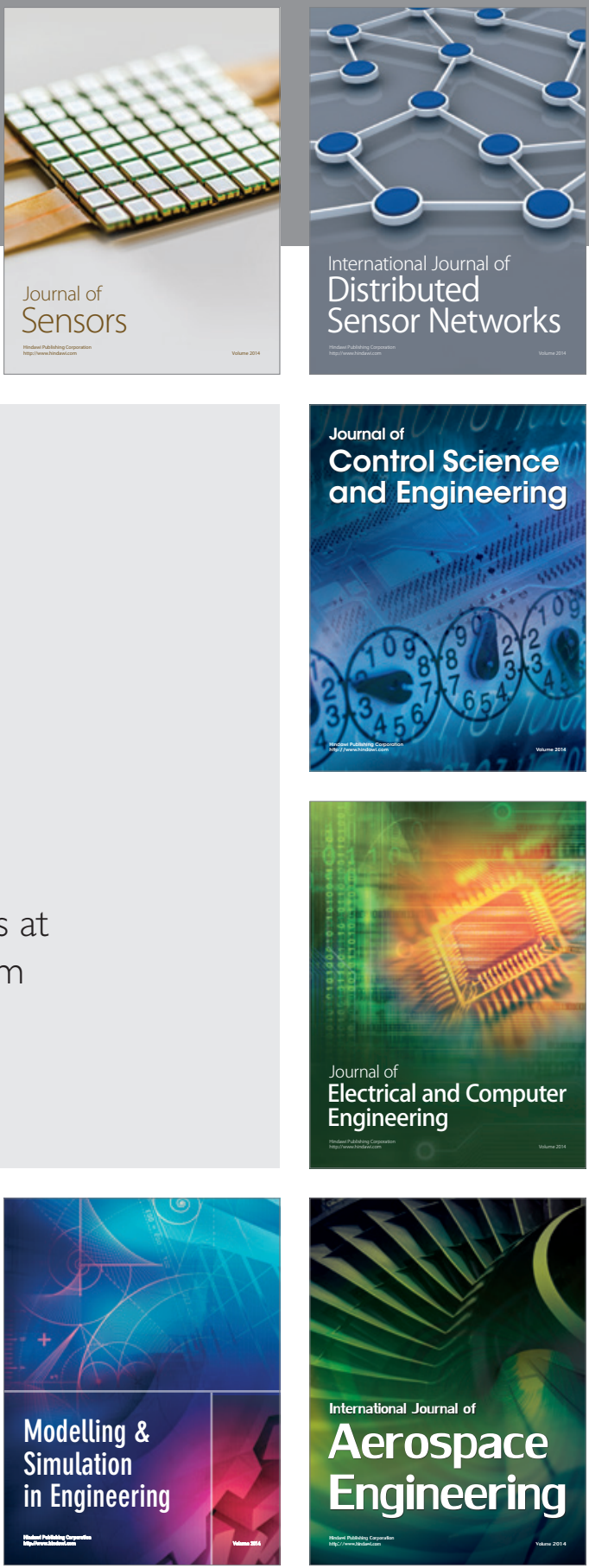

Journal of

Control Science

and Engineering
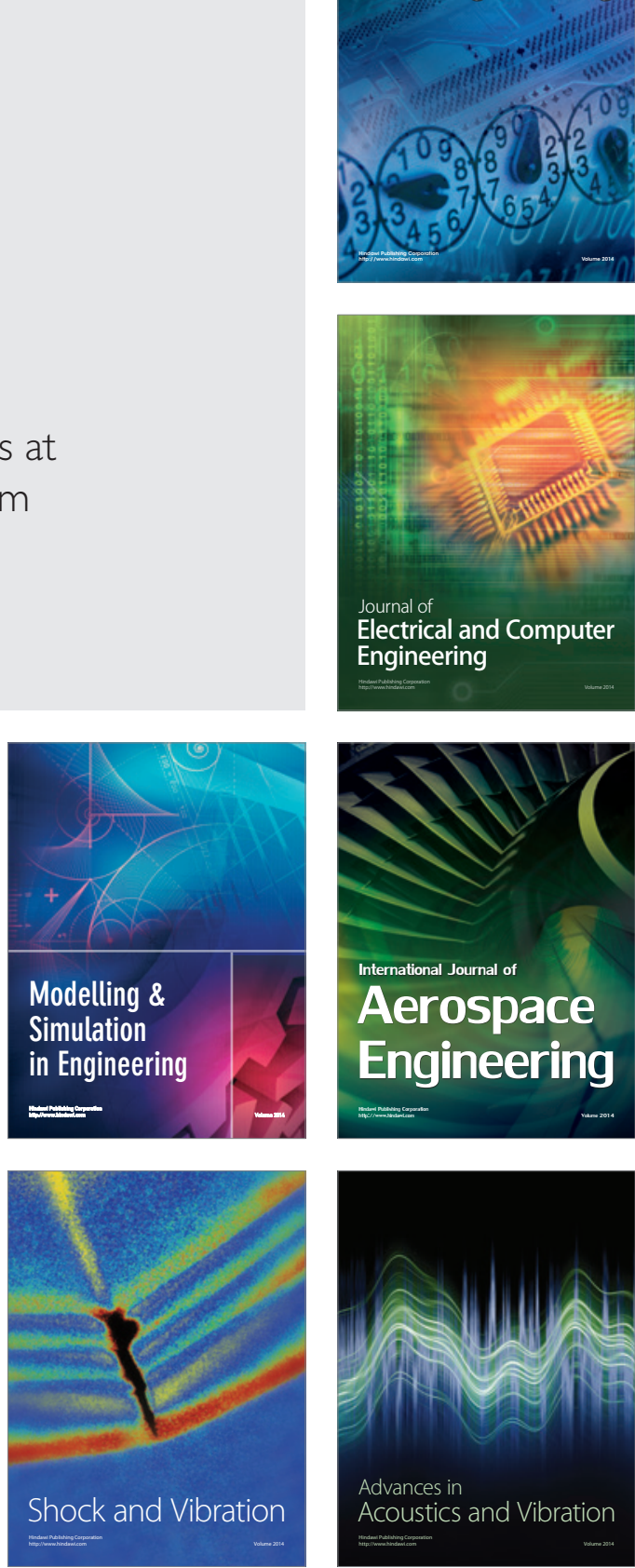